\title{
Research on the Innovated Management Mechanism of Courses Restudying in Universities
}

\author{
Li Hua \\ College of Engineering and Technology, Jilin Agricultural University, Changchun, 130118, China
}

Keywords: Application-oriented; Course restudy; Teaching management; Teaching quality

\begin{abstract}
From the perspective of teaching management in universities, this paper analyzes the curriculum revisions and related data of different types of students in the past three years, and makes a rational thinking on the basic factors that affect the students' restudies. From the four dimensions of student level, teachers, teaching management organization and teaching quality monitoring, it focuses on the internal and external factors that affect the teaching quality of restudied courses, and it puts forward suggestions on the innovated management mechanism suitable for application-oriented universities by combining with the purpose of cultivation of application-oriented talents in universities.
\end{abstract}

\section{Introduction}

The development of universities is a bold exploration and innovation of the mechanism of higher education in China. As a new force in higher education, it has been developing rapidly. It plays a positive role in expanding the resources of higher education, enriching the cultivation of professional talents and supporting local schools and flourishing local economy. In the "13th Five-Year Plan" period, universities are walking on the road of "strengthening the application-oriented construction", catering to the regional economic and industrial transformation and upgrading, the development of public administration and social and cultural construction needs, playing the advantages of academic disciplines, grasping the location characteristics, scientifically positioning talents-cultivating types, innovating the system mechanism, taking the road of the scientific development and comprehensively enhancing the quality of personnel training, to provide high-quality application of technical support and intellectual protection for the economic and social development. However, college students are active in thinking, but their learning initiative is relatively weak. So how to be more effective in their academic guidance has become our top priority. Especially under the premise of decline in the passing rate of curriculum, the students' graduation rate is also affected. How to effectively manage the courses restudying plays a certain role in improving classroom teaching in universities.

\section{Self-recognition, Status Quo of Restudies Courses Teaching and Existing Problems}

Status Quo of Restudies Courses Teaching. Nowadays, on the basis of the credit system, a popular management model in most universities is: if the student failed in the normal test, he will be given a make-up chance at the beginning of the semester. If he failed again, he must participate in the course restudying, until getting the corresponding credits. The students can only graduate after he has got the credits required in the cultivation program. The purpose is to enable students to timely and fully meet the requirements of the teaching plan, so courses restudying are the inevitable product of the credit system. This model has been going on for more than ten years. In the actual teaching process, although it has made continuous improvement, there are still many drawbacks. The most prominent contradiction is how to effectively improve the restudied course passing rate under the premise of ensuing the teaching quality, which is a major problem faced by college teachers and students.

Implementation Process and Organization of the Course Restudying. At the beginning of each semester, the Academic Affairs Department will classify the students who failed the required courses according to the results of the final examinations of the last semester. The universities will 
arrange make-up examination specifically for them, with the purpose to let them get the appropriate course credits in it. After test results are released, the Academic Affairs Department will calculate all the failed required courses for all the students in the year and makes a list of students enrolled in the restudy, and further summarizes the curriculum information sheets on the basis, which mainly include the name of the course, the number of students and whether or not these courses will begin in this semester. If a large number of students need to restudy a certain course but this course will not begin in this semester, in most circumstances, special restudy courses will be set up for these students; for the remaining courses, if there are no special circumstances, it is preferred to encourage the students to join the regular class. The regular classes with restudying students are subject to the required courses offered by the school. The students who cannot attend special restudying class or regular class, need to wait for the next round of restudying. The cycle will go on until the students pass all the failed courses and ultimately achieve the established training objectives before graduation.

Analysis of the Overall Situation of the Three-Year Curriculum Restudying. The author has tracked the restudying in the last three years in universities. From the data in the table, it can be seen that the number of restudied courses and students in each school year is high, reflecting the high overall failure rate and proportion of restudying; about $20 \%$ of the students in each school year enrolled in the restudying courses, and the number of curses is 3-4, reflecting that the restudying students has groupment feature; according to enrollment in each school year, we can get that the restudying passing rate is about $60 \%$, reflecting the low pass rate. Some students need to participate the restudying again.

Table 1 Summary of the Courses Restudying in the Last Three Years

\begin{tabular}{cccccc}
\hline School Year & $\begin{array}{c}\text { Number of } \\
\text { Restudied } \\
\text { Courses }\end{array}$ & $\begin{array}{c}\text { Number of } \\
\text { Restudying } \\
\text { Students }\end{array}$ & $\begin{array}{c}\text { Number of } \\
\text { Courses Per } \\
\text { Capita }\end{array}$ & $\begin{array}{c}\text { Percentage of } \\
\text { Restudying } \\
\text { Students }\end{array}$ & Passing Rate \\
\hline $\mathbf{2 0 1 3 - 2 0 1 4}$ & 5627 & 779 & 3.14 & $18.24 \%$ & $48.70 \%$ \\
\hline $\mathbf{2 0 1 4 - 2 0 1 5}$ & 6848 & 1692 & 3.24 & $16.31 \%$ & $56.68 \%$ \\
\hline $\mathbf{2 0 1 5 - 2 0 1 6}$ & 6314 & 1227 & 3.40 & $13.28 \%$ & $56.11 \%$ \\
\hline
\end{tabular}

Through the data comparison and analysis, the author found that the courses restudying in the recent three years has the following characteristics: first, the number of students increased from low to high grade; second, restudied courses are mainly public basic courses, especially mathematics courses; third, the restudying rate of the same course became higher year after year. Based on the above research background and existing problems, the author believes that the current curriculum restudying mechanism in the credit system model is irreplaceable, and its importance and necessity is self-evident, but there are still flaws. So how to solve the above mentioned problems, effectively strengthen the curriculum restudying management and improve the quality of teaching restudying, is our urgent problem to be solved.

\section{Depth Thinking and Analysis of the Main Factors Affecting the Quality of the Restudied Courses.}

Restudied courses teaching is essentially the same with normal courses teaching, for they are both the teaching and learning process between teachers and students. However, it is not difficult to find that in the actual restudied courses teaching process, there are certain problems in students and teachers, teaching management organizations, teaching quality monitoring and so on, which directly or indirectly affect the teaching quality of restudied courses.

Analysis on Student and Teacher Level Factor. (1). Most of the restudying students have not paid enough attention on studies. Their learning attitude needs to be corrected, and they are lack of 
learning initiative to restudy the courses. On the restudying class, they often come late, leave early, and even skip the class. They think that they have learned and do not need to listen carefully. They have low learning enthusiasm, inefficiency and usually do not want to communicate with the teachers. After class, they do not seriously complete the homework. During the restudying, they do not review in time, with low self-control. If this undisciplined style of study spread, it will seriously affect the quality of courses restudying.

(2) The majority of restudying course teachers is experienced, serious and responsible. They can grasp the scale and teach proper content with flexible teaching methods, but the restudying students is relatively weak in knowledge basis with low learning initiative, so the teachers can't teach students in accordance of their aptitude; thereby the students lost interest in studies. Teaching and learning is a complementary process. If teaching is not good, the students cannot learn well, which naturally affects the quality of restudied courses teaching.

Analysis of Organizational Factors in Teaching Management. Since the arrangement of restudied courses often occurs after that of normal courses, the teaching resources allocated to restudies courses will be relatively scarce. Restudying students come from different grades, in different majors, and the students are less likely to meet each other. It is difficult to implement a relatively unified teaching management. In a sense, the teaching management department does not pay much attention to restudies courses. The lack of teaching supervision is the catalyst for bad discipline in restudying class, low attendance and low passing rate.

Analysis of Teaching Quality Monitoring Factors. The assessment of restudied courses is relatively scattered. Except that some of the follow-up retraining course assessment is to participate in the unified final exam, the assessment for restudying students in special classes are scattered, and its assessment quality is difficult to guarantee. On the other hand, the restudying study belongs to the decentralized study, with each student studying different courses, and the same student may need to restudy a few courses. It is difficult for the teachers, counselors and teaching managers to form unified teaching management and teaching monitoring, therefore, the decentralized management of teaching forms influences the teaching quality to a large extent.

\section{Innovative Management Mechanism Improves the Quality of Curriculum Restudying Teaching Countermeasures}

Restudied courses teaching and normal teaching both play a role to cultivate truly qualified high-quality application-oriented talents. They are in essence the process of teaching and learning. Teaching management department, as a coordinator between teaching and learning, should carefully analyze the causes, gradually improve the rules of the system, improve the management model and promote the management mechanism, in order to effectively guarantee the quality of restudying teaching.

To Strengthen the Professional General Education and Stimulate Learning Motivation. Professional general education is an important part to stimulate the students' learning motivation. Only after the students understand and love their major, they will be studious on it and keep on throughout the whole process of college career. For junior students, professional general education is mainly focused on the basic knowledge of the profession. The specific measures are to develop general education curriculum planning, make general education courses going throughout the university for four years, form a distinctive general education system, cultivate the students' humanities and scientific spirit, carry out general education seminars, exchanges and other activities and publish the students' comprehensive quality test report. This will not only stimulate the learning motivation, but also greatly reduce the rate of restudying and improve the quality of restudying teaching.

To Promote Students' Education Classification and Expand Teaching Them in Accordance with Their Aptitude. Restudied courses should be the same as the normal course in terms of knowledge coverage and teaching difficulty, but they need to be adjusted according to the characteristics of the restudying class. For restudying students, education classification can be 
conducted according to their grades, majors and courses, which is beneficial for the students in different majors and grades to complete restudying.

To Promote The "School-Based" Classroom Teaching Reform. It is necessary to effectively reform the teaching content, make in-depth reform of teaching methods, achieve the teaching model emphasis shift from knowledge input to capacity training, vigorously promote the transfer of classroom, Mooc, mixed teaching and other modern educational methods, focus on cultivating students' interest and innovation of self-study, exploring problems and innovation. For some of the students with weak learning ability, the teachers should use a variety of teaching methods in the classroom teaching to maintain the continuity of the teaching process, and they should also give full play to the students' subjective initiative, let them have appropriate thinking and asking time to achieve the transformation from the "enforced to learn" to "I want to learn", so as to improve the teaching quality.

To Strengthen Academic Guidance and Promote the Normalization of Academic Diagnosis. Each student is different from others, so its learning ability and learning effect are not the same. Restudying students are special groups. They are weak in knowledge basis, but they are sensitive and are bearing heavy pressure. Universities should strengthen the group's academic guidance, and achieve classification, multi-form and efficiency. The specific measures are: for students with poor basis, if necessary, one to one help can be arranged for them; for the students with good knowledge basis, it is necessary to remind them to cherish learning opportunities and correct learning attitude. In addition, there is a need to enhance students' academic responsibility and ability, regularly publish academic early warning data, and promote the normalization of academic diagnosis.

\section{Conclusion}

The application-oriented transformation construction is the only way for universities. The quality of personnel training depends on the quality of classroom teaching. From the perspective of personnel training goal and characteristics, universities should innovate the courses restudying management mechanism, strengthen the management intensity, improve the rules for restudying, promoting courses restudying management model and ensure the quality of restudying teaching, in order to cultivate a truly qualified high-quality application-oriented technical talents.

\section{References}

[1] Zhang Changbin. Analysis and Improvement of Influencing Factors on Courses Restudying in Universities. Heilongjiang Higher Education Research, 2013 (9).

[2] Zhang Jinlong. Reflections on Improve the Restudying Quality under Credit System, 2011 (12).

[3] Liu Haitao, Tang Dongshan. Reflections on the Management Model of Restudying in Universities. Educational Theory Research, 2013 (5).

[4] Jiang Jianhong, He Xiaofeng. Analysis of the Problems Existing in the Reconstruction Management of Universities and Countermeasures. Contemporary Education Forum, 2011 (12).

[5] Zhou Fei. On the Characteristics of College Students and Management Countermeasures. Success (education) .2011-05.

[6] Ma Shandan, Zhou Chun'er. Design of Information Management Sub-system of Adult Higher Education Restudying under the Credit System. Journal of Hubei University Adult Education Journal. 2010-12. 